\title{
PHARMACOKINETICS OF ISOFLAVONES FROM SOY INFANT FORMULA IN NEONATAL AND ADULT RHESUS MONKEYS
}

Daniel R. Doerge ${ }^{* 1}$, Kellie A. Woodling ${ }^{1}$, Mona I. Churchwell ${ }^{1}$, Stefanie C. Fleck ${ }^{1}$, and William G. Helferich ${ }^{2}$

${ }^{1}$ Division of Biochemical Toxicology, National Center for Toxicological Research, U.S. Food and Drug Administration, Jefferson, AR 72079

${ }^{2}$ Department of Food Science and Human Nutrition, University of Illinois, Urbana-Champaign, IL 61810

*Corresponding author at: (870) 543-7943 tel

e-mail daniel.doerge@fda.hhs.gov 


\begin{abstract}
Consumption of soy infant formula represents a unique exposure scenario in which developing children ingest a mixture of endocrine-active isoflavones along with a substantial portion of daily nutrition. Genistein and daidzein were administered as glucoside conjugates to neonatal rhesus monkeys in a fortified commercial soy formula at 5, 35, and 70 days after birth. A single gavage dosing with $10 \mathrm{mg} / \mathrm{kg}$ bw genistein and $6 \mathrm{mg} / \mathrm{kg}$ bw daidzein was chosen to represent the upper range of typical daily consumption and to facilitate complete pharmacokinetic measurements for aglycone and total isoflavones and equol. Adult monkeys were also gavaged with the same formula solution at 2.8 and $1.6 \mathrm{mg} / \mathrm{kg}$ bw genistein and daidzein, respectively, and by IV injection with isoflavone aglycones (5.2 and $3.2 \mathrm{mg} / \mathrm{kg}$ bw, respectively) to determine absolute bioavailability. Significant differences in internal exposure were observed between neonatal and adult monkeys, with higher values for dose-adjusted $\mathrm{AUC}$ and $\mathrm{C}_{\max }$ of the active aglycone isoflavones in neonates. The magnitude and frequency of equol production by the gut microbiome were also significantly greater in adults. These findings are consistent with immaturity of metabolic and/or physiological systems in developing non-human primates that reduces total clearance of soy isoflavones from the body.
\end{abstract}

Key Words: Soy, genistein, daidzein, rhesus monkey, pharmacokinetics, mass spectrometry, neonatal 


\section{Introduction}

In many ways, the major soy isoflavones, genistein and daidzein, are archetypical endocrineactive compounds that act through estrogen receptor binding (ER $\alpha$ and $\beta$ ). The role for such chemicals in the etiology of many human disease states has been discussed widely, if inconclusively (National Research Council, 1999; Nohynek et al., 2013; World Health Organization, 2013). Isoflavones, which occur in plants as their glucoside conjugates (Schemes 1 and 2), are extensively distributed in the diets of humans and livestock across cultures that embrace traditional and commercial foods. While estrogenic effects from consumption of isoflavone-rich foods are often associated with beneficial effects in adult humans (reviewed in Messina, 2014; Lagari and Levis, 2014), a body of evidence for both adverse and beneficial effects on breast cancer has been reported in adult animal models treated with isoflavones (reviewed in Helferich et al., 2008); however, other concern comes from exposures during the perinatal period when the potential for altered organizational programming may confer increased susceptibility for diseases later in life (reviewed in Chen and Rogan, 2004; NTP, 2010).

The fetal and neonatal windows of susceptibility to the estrogenic effects of isoflavones can also reflect maturation of processes that serve to detoxify genistein and daidzein through metabolism and excretion (Coughtrie et al., 1988; Falk, 1955; Ginsberg et al., 2002; Strassburg et al., 2002), so perinatal pharmacokinetics can be a critical element of risk assessment (Mattison et al., 2014). Consumption of soy infant formula has long been recognized as a unique human exposure setting given that: many organ systems in mammals continue to develop during the neonatal period (Strassburg et al., 2002; Clancy et al., 2007); a large percentage of total caloric intake is provided by a single source that is rich in isoflavones (20-50 mg total isoflavones per day); and an estimated 10-25\% of all children in the U.S. are so fed (reviewed in Chen and Rogan, 2004; Cao et al., 2009; NTP, 2010; Vandenplas et al., 2014). The internal exposure measurements (mean spot plasma concentrations of total genistein and daidzein of 2.5 and $1.2 \mu \mathrm{M}$, respectively) reported by Setchell et al. (1997) in 4-month-old infants consuming soy formula (6-9 $\mathrm{mg} / \mathrm{kg} \mathrm{bw}$ total isoflavones per day) have provided a benchmark against which many animal studies have been designed and interpreted (e.g., NTP, 2008a; NTP 2008b). These measurements in infants have been replicated and extended in a subsequent study by Cao et al. (2009). Nonetheless, in 2010, the National Toxicology Program and its expert panel concurred "that there is minimal 
concern for adverse effects on development in infants who consume soy infant formula" (https://www.niehs.nih.gov/health/topics/agents/sya-soy-formula/; NTP, 2010; McCarver et al., 2011), based in part on insufficient evidence for a conclusion from experimental animal studies of soy infant formula, soy diet, soy protein isolate, mixtures of isoflavones, daidzein, glycitein, or equol but also clear evidence of adverse developmental effects in experimental animal studies with genistein (e.g., NTP, 2008a; NTP 2008b).

The serum pharmacokinetics of isoflavones and their glucoside conjugates have been studied in adult, pregnant, lactating, and neonatal rats, mice, and adult humans (Chang et al., 2000; Bloedon et al., 2002; Setchell et al., 2003; Doerge et al., 2006; Jefferson et al., 2009; Andrade et al., 2010). Unfortunately, limitations in study design often make many of these studies of limited value for risk assessment of human exposures through food, particularly soy formula (Doerge et al., 2002). The current study in rhesus monkeys (Macaca mulatta) uses an experimental design that includes: comparison of oral dosing with isoflavone glucosides in a soy infant formula between adults and several ages of neonates, starting shortly after birth; use of a dose within the range of proposed human exposure that is high enough to measure both aglycones (i.e., active) and conjugated (i.e., inactive) forms of isoflavones in serum; determinations using sensitive and specific LC/MS/MS methodology; and evaluation of oral and intravenous (IV) routes of administration in adults. The many known similarities to humans in physiology, metabolism, and pharmacology make the developing non-human primate model particularly appropriate to evaluate isoflavone serum pharmacokinetics and fill important data gaps for risk assessment of soy infant formula (Chellman et al., 2009), given the unlikely

prospect of conducting such detailed studies in human infants (Setchell et al., 1997; Cao et al., 2009).

2. Methods

\subsection{Reagents.}

Sigma Chemical Co. (St. Louis, MO) supplied all biochemical reagents. All solvents were HPLC grade and Milli-Q water was used throughout.

\subsection{Soy Infant Formula and Mixed Soy Isoflavones.}


The mixed isoflavone preparation was prepared from recrystallization of Novasoy (Archers Daniel Midland Co., Midland, IL) as previously described (Allred et al., 2005). The preparation contained predominantly glycosylated forms of soy isoflavones comprised of $29 \pm 0.21 \%$ by weight genistein, of which $4 \%$ was aglycone, and $16 \pm 0.15 \%$ by weight daidzein, of which $10 \%$ was the aglycone, as quantified by LC/MS/MS with and without methanolic acid hydrolysis as previously described (Doerge et al., 2000).

Enfamil Prosobee was obtained from a local grocery store and determined to contain $36 \pm 5.9$ $\mu \mathrm{g} / \mathrm{g}$ genistein and $18 \pm 4.2 \mu \mathrm{g} / \mathrm{g}$ daidzein by LC/MS/MS after methanolic acid hydrolysis. The basal powdered formula was fortified with mixed soy isoflavones as described below and reconstituted with distilled water according to the package recipe of $8.8 \mathrm{~g}$ per 2 fluid ounces $(0.15 \mathrm{~g} / \mathrm{ml})$.

\subsection{Animal Handling Procedures.}

Procedures involving care and handling of non-human primates were reviewed and approved by Institutional Animal Care and Use Committees at both Alpha Genesis Inc. (Yemassee, SC; where the dosing and sampling were conducted) and at the National Center for Toxicological Research (NCTR, Jefferson, AR; where the analyses were performed). Adult monkeys that had been maintained on soy-containing diets were placed on a fruit-only diet approximately $24 \mathrm{~h}$

prior to dosing, but low residual levels of isoflavones and equol were observed in most pre-dose serum samples.

\subsection{Dose Selection and Blood Sampling Regimen.}

The IV dose levels of genistein and daidzein were selected based on maximal solubility of the isoflavones in primarily aqueous medium (see below), the need to measure aglycone forms in serum throughout a 24-h period, and an appropriate volume of injection (see below). The ratio of genistein:daidzein was selected to represent the range found in soy products and present in the mixed isoflavones preparation used in oral dosing (see below). The IV dosing solution was prepared by dissolving a weighed portion of genistein $(375 \mathrm{mg})$ and daidzein $(225 \mathrm{mg})$ in $75 \mathrm{ml}$ DMSO before dilution in $75 \mathrm{ml}$ water (50\% total volume). The concentration of the dosing solution was measured by LC/MS/MS at $2.6 \pm 0.16 \mathrm{mg} / \mathrm{ml}$ genistein and $1.6 \pm 0.058 \mathrm{mg} / \mathrm{ml}$ 
daidzein (mean $\pm \mathrm{SD}, \mathrm{n}=3$ ), and was determined to be stable for at least 2 months at ambient conditions (data not shown). All dosing was complete within 1 month using a single dosing solution. Doses of $5.2 \mathrm{mg}$ genistein and $3.2 \mathrm{mg}$ per $\mathrm{kg}$ bw were administered intravenously (administered volume $=2 \mathrm{ml} / \mathrm{kg}$ bw) into the femoral vein during brief ketamine anesthesia (10$20 \mathrm{mg} / \mathrm{kg}$ bw IM).

An oral dosing solution was prepared by fortifying commercial infant formula (Enfamil Prosobee) with mixed soy isoflavones, as described above. Weighed aliquots of the solid fortified formula sufficient for dosing individual monkeys were stored in a refrigerator until the time of dosing when a vial was rehydrated to the requisite volume. All dosing was complete within 1 month of the fortified formula preparation and the solid formula was determined to be stable at refrigerator temperature for at least 2 months by performing repeated LC/MS/MS quantitative analysis (data not shown). For neonatal monkeys, target doses of $10.4 \mathrm{mg} / \mathrm{kg} \mathrm{bw}$ genistein and $6.0 \mathrm{mg} / \mathrm{kg}$ bw daidzein were prepared for delivery in $20 \mathrm{ml}$ formula per $\mathrm{kg}$ of bw, $0.15 \mathrm{~g}$ formula per $\mathrm{ml}$, or $3 \mathrm{~g}$ formula administered per $\mathrm{kg}$ bw (i.e., no more than $\sim 20 \mathrm{ml}$ total). The doses administered were determined for adult monkeys based on the same concentrations used for neonates and an appropriate volume for delivering by gavage (i.e., no more than $\sim 40 \mathrm{ml}$ total). The adult dosing regimen was within two-fold of that extrapolated from the neonatal (PND5) dosing regimen using allometry (e.g. 2.8 versus $5.4 \mathrm{mg} / \mathrm{kg}$ bw for genistein, see Table $\mathrm{S} 3)$. The adult target doses of $2.8 \mathrm{mg}$ genistein and $1.6 \mathrm{mg}$ daidzein per $\mathrm{kg}$ bw were prepared for delivery in $5 \mathrm{ml}$ formula per $\mathrm{kg} \mathrm{bw}, 0.15 \mathrm{~g}$ formula per $\mathrm{ml}$, or $0.75 \mathrm{~g}$ formula administered per $\mathrm{kg}$ bw. The genistein and daidzein contents in the fortified formula were quantified by LC/MS/MS after methanolic acid hydrolysis of glucosides as previously described (Doerge et al., 2000) at $3.7 \pm 0.57 \mathrm{mg}$ genistein and $2.1 \pm 0.51 \mathrm{mg}$ daidzein per $\mathrm{g}$ formula (mean $\pm \mathrm{SD}, \mathrm{n}=3$ ). Actual doses delivered were $2.8 \mathrm{mg}$ genistein and $1.6 \mathrm{mg}$ daidzein per $\mathrm{kg}$ bw as determined by calculating the volume of formula administered from the daily measured bw, based on $5 \mathrm{ml} / \mathrm{kg}$ bw for adults and $20 \mathrm{ml} / \mathrm{kg}$ bw for neonates, and were within $5 \%$ of the target dose in all cases. Five adult male rhesus monkeys of unspecified age with body weights (bw) of 5.2-8.36 kg were obtained from the Alpha Genesis colony (Table S1). Five male neonatal monkeys were treated orally on postnatal day (PND) 5, four on PND 35, and four on PND 70 using procedures described above. Body weights were not completely transcribed but ranged from 0.44-0.56, 0.70, 
and $0.73-1.13 \mathrm{~kg}$, respectively (Table S2). The mean and ranges of body weights for these monkeys are similar to those recorded in a previous study that used the same ages (PND5, 0.50, 0.44-0.60; PND35, 0.67, 0.48-0.98; PND70, 0.83, 0.78-1.17 kg) with 9 monkeys (unpublished).

Therefore, the adult dosing regimen, which was selected primarily for technical reasons, was similar to that extrapolated using allometry, which is based on body weight differences alone between adult and newborn monkeys (see Table $\mathrm{S} 3$ where an example is shown whereby a larger body weight-adjusted dose of genistein is required to produce the same AUC in a smaller animal). In all cases, serial blood samples were collected from the cephalic vein at each of the designated time points for IV $(0.083,0.25,0.5,1,2,4,6,8$, and $24 \mathrm{~h})$ and gavage administration $(0.5,1,2,4,6,8$, and $24 \mathrm{~h})$. Pre-dose blood was drawn from each monkey for use as the 0 time point. Blood samples were allowed to clot at room temperature and serum was produced by centrifugation. Samples were frozen and stored at $-80{ }^{\circ} \mathrm{C}$ until shipment on dry ice to the NCTR where they were stored at $-80{ }^{\circ} \mathrm{C}$ until analyzed.

\subsection{LC-ES/MS/MS Analysis of Isoflavones in Serum.}

Analysis of aglycone and total soy isoflavones and equol was performed by using a validated high throughput LC-ES/MS/MS method (Twaddle et al., 2002). Briefly, isotopically labeled internal standards were added to each thawed serum sample (10-100 $\mu$ l), then samples were purified using supported liquid extraction in 96-well plates (400 mg SLE+, Biotage, Charlotte, NC) and analyzed using LC-ES/MS/MS in the multiple reaction monitoring mode by monitoring specific transitions for labeled and unlabeled analytes. Method validation included replicate analysis of spiked serum at levels from $0.4-40 \mathrm{nM}$, with accuracy and precision ranging from 89105\% and 2.8-18\%, respectively. The method detection limits (LOD) for daidzein, genistein, and equol contained in $100 \mu \mathrm{l}$ of serum, defined as a signal/noise ratio of $\geq 3$, were approximately 2-3 nM. Samples containing undetectable levels of isoflavones were treated as 0 for purposes of mean determinations.

In addition to the inherent specificity that comes from adding isotopically labeled internal standards to every serum sample prior to sample preparation and analysis, further quality control measures were performed during every sample set and included the replicate analysis of 
procedural blanks, a pooled serum sample from soy-treated rats containing primarily conjugated forms of isoflavones, blank injections, and injections of authentic standards.

\subsection{Enzymatic Hydrolysis of Isoflavone Conjugates.}

Total serum concentrations of soy isoflavones (i.e., aglycone + Phase II conjugates) were quantified following incubation with a $H$. pomatia glucuronidase/sulfatase mixture (Sigma Sulfatase H-1, 2 units/assay). This preparation contains sufficient glucuronidase ( $\geq 300 \mathrm{units} / \mathrm{mg}$ protein) and sulfatase ( $\geq 10$ units/mg protein) activity for total conjugate hydrolysis. The time course for deconjugation of isoflavones was determined from $0.5-24 \mathrm{~h}$ incubations using a pooled serum sample obtained from rats consuming a soy-based diet. Maximal enzymatic hydrolysis was observed after 2-4 h for the mixed glucuronidase/sulfatase activities and incubations were conducted overnight to ensure complete hydrolysis. The respective aglycones were determined without enzymatic treatment. Aliquots of each serum sample were analyzed for aglycone $(\leq 100 \mu \mathrm{l})$ and total $(\geq 10 \mu \mathrm{l})$ genistein, daidzein, and equol.

\subsection{Pharmacokinetic Analysis.}

Plots of serial serum concentrations of total and aglycone isoflavones and total equol vs. time following administration to individual monkeys were analyzed using model-independent pharmacokinetic analysis (PK Solutions 2.0 software, Summit Research Services, Montrose, $\mathrm{CO}$ ). Natural log-linear plots were fit to up to three kinetic phases corresponding to elimination, distribution, and absorption. The first-order elimination rate constants $\left(\mathrm{k}_{\mathrm{elim}}\right)$ were determined from the terminal slope of the respective curve and the first-order distribution or absorption rate constants were determined after subtracting the contribution from the terminal elimination phase of the respective curve. Internal exposures were determined as $\mathrm{AUC}_{0-24}$ by using the trapezoidal rule to avoid possible bias from extrapolation beyond the data, or as $\mathrm{C}_{\max }$, which was determined by visual inspection. The volume of distribution $\left(\mathrm{V}_{\mathrm{d}}\right)$ and total clearance $\left(\mathrm{Cl}_{\text {tot }}\right)$ values were calculated from IV administration data using the relationships: $\mathrm{V}_{\mathrm{d}}=\operatorname{dose} /\left(\mathrm{AUC}_{0-24} \mathrm{x} \mathrm{k}_{\text {elim }}\right)$ and $\mathrm{Cl}_{\text {tot }}=$ dose $/ \mathrm{AUC}_{0-24}$, respectively, because a reliable $\mathrm{AUC}_{0-\infty}$ value was not available. Half-times were determined from rate constants using the relationship: half-life $=\ln 2 / \mathrm{k}$. Absolute bioavailability (fraction absorbed, f) was calculated for individual monkeys from the ratio of $\mathrm{AUC}_{0-24}$ for oral administration compared to the $\mathrm{AUC}_{0-24}$ for $\mathrm{IV}$ administration after 
normalizing for the different doses used for the two routes. All data points collected were used for the graphical analyses described.

\subsection{Statistical Analysis.}

Age-related differences in pharmacokinetic parameters between adult and neonatal monkeys were assessed using one-way ANOVA, with and without log transformation, of the target parameter using age as the grouping variable (SigmaStat). Dunnett's test was used to adjust for multiple comparisons in pairwise analysis between adult group parameters and those from groups of each age of neonatal monkeys. Repeated measures ANOVA was used to test for significant changes in PK parameters of individual neonatal monkeys at the 3 different ages using the Holm-Sidak method for pairwise comparisons. The data for AUC-Equol/AUCDaidzein, with and without log transformation, were not normal so ANOVA on ranks was performed using the Kruskal-Wallis test and Dunn's method for pairwise comparisons. Differences were deemed significant for $\mathrm{p}<0.05$.

\section{Results}

\subsection{Dosing in Adult Monkeys}

Figure 1 shows average log vs. time plots of aglycone and total isoflavone concentrations (mean $\pm \mathrm{SD}$ ) following administration of an IV dose of $5.2 \mathrm{mg} / \mathrm{kg}$ bw genistein and $3.2 \mathrm{mg} / \mathrm{kg}$ bw daidzein to adult male rhesus monkeys $(n=5)$. This dosing led to rapid distribution of the parent aglycone from serum $\left(\mathrm{t}_{1 / 2 \text { Distr }}=0.35 \pm 0.14\right.$ and $0.24 \pm 0.08 \mathrm{~h}$, respectively) with a slower terminal elimination phase $\left(\mathrm{t}_{1 / 2 \mathrm{Elim}}=12 \pm 9.2\right.$ and $1.4 \pm 0.44 \mathrm{~h}$, respectively, Tables 1 and 2$)$. Total isoflavones (i.e., aglycone plus Phase II conjugates) showed elimination phase kinetics that were faster for genistein but slower for daidzein. At early sampling times (5-30 min), the fraction of total isoflavones in serum present as the aglycone (i.e., the dosing forms) was in the range $30-50 \%$ (not shown). The fraction of total $\mathrm{AUC}_{0-24}$ represented by the aglycone form was $17 \pm 7.2 \%$ for genistein and $17 \pm 8.7 \%$ for daidzein. Small secondary peaks were observed for total, but not aglycone genistein and daidzein profiles in two of the five monkeys in the $0.5-4 \mathrm{~h}$

time points, which could be consistent with enterohepatic recirculation. The formation of equol was observed in all five monkeys (range 0.2-2.2 $\mu \mathrm{M}$ ), with peaks in total equol concentration 
appearing 4-24 $\mathrm{h}$ after the injection (Table 3 and Figure 2). Unconjugated equol was not detected in any sample (LOD, $3 \mathrm{nM})$.

\subsection{Oral Dosing in Adult Monkeys}

Administration of isoflavone glucosides by gavage $(2.8 \mathrm{mg} / \mathrm{kg}$ bw genistein and $1.6 \mathrm{mg} / \mathrm{kg} \mathrm{bw}$ daidzein in soy infant formula) to adult male monkeys $(n=4)$ resulted in rapid absorption, most often maximal at the 30 min time point, followed by a rapid loss of parent aglycone $\left(\mathrm{t}_{1 / 2 \mathrm{Elim}}=1.4\right.$ $\pm 1.9 \mathrm{~h}$ for genistein and $1.0 \pm 0.89 \mathrm{~h}$ for daidzein) and much slower elimination of total isoflavones $\left(\mathrm{t}_{1 / 2 \mathrm{Elim}}=3.7 \pm 0.61 \mathrm{~h}\right.$ for genistein and $3.0 \pm 2.3 \mathrm{~h}$ for daidzein; Tables 1 and 2 , respectively). Values for $C_{\max }$ were determined in individual monkeys for which the $T_{\max }$ values varied between 4 and $8 \mathrm{hr}$. Figure 3 shows the average concentration-time profiles for total and aglycone isoflavones after oral administration. The percentages of total $\mathrm{AUC}_{0-24}$ represented by the aglycone forms were $2.5 \pm 1.5 \%$ for genistein and $2.5 \pm 2.7$ for daidzein $(n=4)$. The fractions absorbed, defined as $\mathrm{f}=$ dose-normalized $\mathrm{AUC}_{0-24}$ oral $/ \mathrm{AUC}_{0-24 \mathrm{IV}}$, for the parent aglycones were $0.025 \pm 0.011$ for genistein and $0.039 \pm 0.029$ for daidzein $(n=4)$; this ratio for total isoflavones was much higher $(0.36 \pm 0.24$ for genistein and $0.42 \pm 0.23$ for daidzein, $n=4)$. As from the IV data, evidence for enterohepatic recirculation, as indicated by large secondary peaks in total genistein and daidzein in the $2-8 \mathrm{~h}$ time range, was observed in all four monkeys (not shown).

The gut microbiome-mediated formation of equol was observed in all four adult monkeys, with peaks in total equol concentration appearing 6-24 $\mathrm{h}$ after dosing and subsequent to the peaks in serum total daidzein concentration (Figures 3 and 4). The AUC ratio for total equol to total daidzein after oral administration ranged from 0.7-8 and equol would have likely exceeded daidzein in all monkeys if its calculation had been extrapolated to longer times; the corresponding range after IV administration was 0.08-1.6. The total equol $\mathrm{AUC}_{0-24}$ values for oral administration were approximately double those for IV dosing, when calculated on a doseadjusted basis (note: values in Table 3 are not adjusted for dose). The conversion of daidzein to equol, as measured by the ratio of serum AUCs (AUC-Eqol total/AUC-Daidzein total), was extensive $(5.0 \pm 3.5$, Table 3$)$, observed in every monkey, and greater than following IV 
administration $(1.0 \pm 0.57$, Table 3$)$. As with the IV exposure, unconjugated equol was not observed in any serum sample after oral dosing (LOD $3 \mathrm{nM}$ ).

\subsection{Oral Dosing in Neonatal Monkeys}

Individual male neonatal monkeys were treated with $10.4 \mathrm{mg} / \mathrm{kg}$ bw genistein and $6.0 \mathrm{mg} / \mathrm{kg}$ bw daidzein by gavage on PNDs 5, 35, and 70. Figure 5 shows the mean ( \pm SD) time-serum concentration profiles for aglycone and total genistein and daidzein in PND 5 monkeys and Figure 6 shows the analogous profiles for total genistein, daidzein, and equol. Identical data from the other ages were also analyzed (Figures S1-2). Tables 4 and 5 show the derived pharmacokinetic parameters for genistein and daidzein, respectively. The serum concentrations of aglycone and total isoflavones were consistently higher in neonates vs. adult monkeys, even after adjusting for the different doses of isoflavones administered.

Evidence for significant differences between adult and the neonatal monkey groups was observed for several PK parameters related to both genistein and daidzein aglycones (e.g., $\mathrm{t}_{1 / 2 \text { Elim, }}$ $\mathrm{AUC}_{0-24}, \mathrm{C}_{\mathrm{max}}$ ) using one-way ANOVA (Tables 4 and 5, Figures 7 and 8) or between neonates at different ages using repeated measures ANOVA (AUC for total and aglycone daidzein, AUC for total genistein, $\mathrm{C}_{\max }$ for aglycone daidzein). These differences manifested as increased internal exposures for the active isoflavone aglycones in neonatal monkeys when compared with adults. However, there was no evidence that the degree of Phase II conjugation was affected by developmental age from PND 5 to adulthood, since the percentage of aglycone genistein and daidzein in either internal exposure metric (i.e., $\mathrm{AUC}_{0-24}$ or $\mathrm{C}_{\max }$ ) was in the same range (i.e., 24\%; Figures 7 and 8). Significantly decreased half-times (i.e., faster) for terminal elimination of genistein and daidzein aglycones were also observed in adults when compared to neonatal monkey groups (Figure S3). The role of age on the magnitude of UGT vs. SULT conjugation reactions was investigated but no differences were observed between serum levels of glucuronides vs. sulfates for genistein, daidzein, or equol across neonatal and adult ages (not shown).

The frequency of equol formation varied among individual neonatal monkeys sampled at all ages: 2 of 4 produced equol on PND 5; 3 of 4 on PND 35; and 4 of 4 on PND 70 (Figure S4). 
Also, the magnitude of equol formation from daidzein (i.e., the AUC ratio) was lower in all ages of neonatal monkeys when compared to that in adult monkeys, significantly by pairwise comparison at only PND 5 (Tables 2 and 5, Figure 8). By PND 70, mean equol formation from daidzein was approximately 5 -fold lower than in adults. Furthermore, repeated measures ANOVA showed significant age-related increases in the formation of equol across neonatal ages, which was manifested as a regular increase in the mean AUC ratio for total equol/daidzein (Table 5, Figure S4). Identical to adult monkeys, the equol present in every serum sample from neonatal monkeys was conjugated.

\section{Discussion and Conclusions}

\subsection{Isoflavone Pharmacokinetics in Adult Monkeys}

The pharmacokinetics of aglycone isoflavones in adult monkeys following IV dosing are characterized by rapid initial distribution phases (mean half-times 0.35 and $0.24 \mathrm{~h}$ for genistein and daidzein, respectively), large volumes of distribution (mean 35 and $5.9 \mathrm{~L} / \mathrm{kg}$ for genistein and daidzein, respectively), and elimination (mean half-times 12 and $1.4 \mathrm{~h}$ for genistein and daidzein, respectively). This kinetic profile probably reflects the distribution of lipophilic parent compound out of the circulation into tissues where it is further conjugated before elimination. The high degree of conjugation observed at early time points (50-70\%) and in the total AUC (17\% aglycone for both genistein and daidzein) is consistent with efficient systemic Phase II metabolism in the liver and other tissues. The long half times for elimination of total genistein and daidzein from serum could reflect the impact of enterohepatic recirculation on extending terminal levels. Furthermore, the observation of conjugated, but not unconjugated, equol in serum of all injected monkeys with peaks in the 4-24 hr time scale and with AUCs equivalent to those for daidzein ( $\mathrm{AUC}$ ratio $=1$, Table 3 ) is best interpreted as resulting from biliary secretion of daidzein conjugates into the intestine where microbial deconjugation and reduction produces equol, which is absorbed and conjugated in enterocytes before portal vein delivery to the liver for additional metabolism before entry into the circulation. Similarly, limited metabolism of daidzein to equol was observed in female, but not male, rats injected with soy isoflavones (10 $\mathrm{mg} / \mathrm{kg}$ bw IV, Sepehr et al., 2007); however, no equol formation was observed after IV administration of daidzein to Balb/c mice $(0.55 \mathrm{mg} / \mathrm{kg}$ bw, Andrade et al., 2010). 
A consistent body of evidence supports the bioavailability of ingested isoflavone glucoside conjugates through the action of bacterial and intestinal $\beta$-glucosidases present in the GI tract that liberate the parent aglycones, which can be absorbed and subjected to further metabolism either within enterocytes or systemically (Schemes 1 and 2; Zhang et al., 2007). Indeed, the absolute bioavailability of dietary genistein and daidzein glucosides from soy protein isolate was similar to that for gavage of the parent aglycones, based on comparisons of AUCs with that for IV dosing (Andrade et al., 2010).

In the current study, oral administration of a mixture of glucoside forms of soy isoflavones to adult monkeys produced much lower serum concentrations of aglycone and total isoflavones when compared with IV ingestion of the individual aglycones, on a molar dose-adjusted basis (Figures 1-4). The fraction of total isoflavones present in blood as aglycones was substantially lower following oral administration, with mean AUC fractions of $2.5 \%$ for both genistein and daidzein (ranges $0.9-4.0 \%$ and $0.7-6.4 \%$, respectively). This phenomenon is well-described for polyphenolics like isoflavones and is understood to result from extensive pre-systemic Phase II metabolism in the GI tract prior to portal vein delivery to the liver for additional metabolism before entry into the circulation (Sfakianos et al., 1997; Zhang et al., 2007). In addition to the variability associated with measuring the lower resulting concentrations of genistein and daidzein, the impact of what appeared to be enterohepatic recirculation further complicated the kinetic analysis after oral administration (secondary peaks around $4 \mathrm{~h}$, Figure 3 ). Based on the dose-adjusted AUCs for oral vs. IV, the absolute bioavailability of aglycone genistein and daidzein were 2.5 and $3.9 \%$, respectively, and total systemic availability of genistein and daidzein were 36 and $42 \%$, respectively (Tables 1 and 2). The absolute bioavailabilities for genistein and daidzein aglycones in adult monkeys are lower than those reported for adult rodents, including Balb/c mice (3-5\% for genistein and 7\% for daidzein, Andrade et al., 2010), FVB mice (23\% for genistein, Yang et al., 2010), Sprague-Dawley rats (19-34\% for genistein, Zhou et al., 2008) and Wistar rats (7-15\% for genistein, Coldham et al., 2002a). While the absolute bioavailability of isoflavones has not been reported for humans, Bloedon et al. (2002) reported low aglycone percentages in serum AUCs for genistein and daidzein after oral administration to post-menopausal women (mean values of 0.49 and $0.85 \%$, respectively). The values for total systemic availability below $50 \%$ probably reflect an uncertain extent of 
absorption from and reductive/ring-fission metabolism in the GI tract (Schemes 1 and 2) that is consistent with the extensive metabolism of genistein and daidzein by human and rat fecal preparations (Coldham et al., 2002b) and the low recovery of genistein and daidzein (as conjugates) reported in human urine (30-40 and 10-15\% of administered doses, respectively (Bloedon et al., 2002; Setchell et al., 2003).

\subsection{Equol Formation in Adult Monkeys}

Unlike adult humans, of whom only a limited subset can convert daidzein to equol, but like other common experimental animals, including adult rats, mice, and pigs that consistently produce equol (Gu et al., 2006), all adult monkeys produced equol after daidzein gavage. While no consensus exists for the role of equol in any effect from soy isoflavones in humans or experimental animals (Gu et al., 2006; Ju et al., 2006), this major difference in equol formation between humans and experimental animals remains a significant barrier to interpretation. The amounts of total equol produced from oral dosing were similar to those from the IV dosing, with maximal total levels observed in the 4-24 hr samples that exceeded the maximal levels of total daidzein and genistein (Figure 4). The mean dose-adjusted AUC for total equol was 2-fold higher for the oral route vs. IV and the equol/daidzein AUC ratio was 5-fold higher (Table 3). This apparent route-dependence could reflect the additional mode of daidzein delivery to the gut microflora (dosing + biliary for oral vs. biliary alone for IV). Nonetheless, and despite a high degree of analytical sensitivity ( $\mathrm{LOD}=3 \mathrm{nM}$ ), the serum concentrations of unconjugated equol were consistently undetectable following either route of administration $(<0.1 \%)$. This apparent difference with daidzein and genistein, where aglycones were routinely observed in serum in the 2-3\% range, probably results from more efficient Phase II metabolism of equol in the GI tract and liver (Allred et al., 2005), which is consistent with the absence of estrogen receptor-mediated effects from equol in some animal models (Ju et al., 2006).

\subsection{Isoflavone Pharmacokinetics in Neonatal Monkeys}

The pharmacokinetics of isoflavones administered orally as glucosides in soy infant formula showed evidence for age-related differences that produced higher internal exposures in the youngest monkeys. The magnitude of these differences was in excess of minor changes in body weight-adjusted doses predicted by allometry alone (Table S3) and suggests immaturity of 
important physiological/biochemical functions related to total clearance of isoflavones from the body (e.g., Phase II metabolism in GI tract and liver, reductive/ring fission metabolism in the GI tract, transporters, and excretion via feces and urine). Such immaturity does not appear to include Phase II conjugation of genistein, daidzein, or equol, since the 2-3\% of total isoflavones and $<0.1 \%$ equol present in serum as aglycones did not differ between neonatal and adult monkeys (Figures 7 and 8). Similarly, no differences between the percentages of total isoflavones and equol present in serum as either the individual glucuronide or sulfate metabolites were observed at any age. This observation differs from a pharmacokinetic analysis of genistein/genistin in neonatal mice where oral administration on PND5 produced aglycone/total AUC percentages in serum of $13-28 \%$, which was in the same range as the $22 \%$ produced by subcutaneous injection (Jefferson et al., 2009), 53\% in PND1-2 rats (Doerge et al., 2001), 3\% in PND10 rats (Doerge et al., 2006), and 3-5\% in adult mice (Andrade et al., 2010). A similar finding, which was attributed to the immaturity of Phase II conjugation in neonatal rodents but not neonatal monkeys, was previously reported for bisphenol A (Doerge et al., 2011). The current study in a developing neonatal monkey model shows that immaturity in metabolic/physiological factors beyond Phase II conjugation can also lead to higher internal exposures to soy isoflavones.

\subsection{Equol Formation in NeonatalMonkeys}

The frequency and magnitude of conversion of daidzein into equol by neonatal and adult monkeys was also highly dependent on age, suggesting a maturation process was required for colonization of the gut by a microbiome capable of mediating this conversion. However, by PND70 all monkeys produced equol, as was observed in adults, albeit at a lower level. These findings suggest that equol production in different species should be considered in the context of age, not an inherent "metabolic phenotype" assembled from animals of different ages (Gu et al., 2006). Consistent with the low frequency of equol production in adult humans, only a fraction of human infants consuming soy formula produced measurable equol in plasma, albeit at levels 2-3 orders of magnitude lower than those of total genistein and daidzein, (57\%, Setchell et al., 1997) or in urine (5\%, Cao et al., 2009). The extensive conjugation of equol and low serum concentrations observed in the neonatal monkey model, relative to genistein and daidzein, make it unlikely that equol would contribute to any effect of soy formula in vivo, irrespective of 
receptor binding potency in vitro (Allred et al., 2005; Ju et al., 2006). The neonatal development of a microbiome supporting the reductive metabolism of daidzein to equol in the rhesus monkey model could reflect a similar developmental colonization by bacterial species involved in other reductive/ring fission reactions that are important for clearance of isoflavones from the body (Schemes 1 and 2; Nichols et al., 2012). The variability in extent and magnitude of equol production seen between individual neonatal monkeys (Figure S4) emphasizes the uncertainties surrounding the factors responsible for microbiome development in young monkeys. Furthermore, it would be similarly imprecise to extrapolate putative effects from this study in monkeys directly to microbiome development in human infants since there are many individual physiological and ecological variables involved. Finally, the profound differences between soy infant formula and breast milk feeding should be evaluated critically before interpreting any possible effect on isoflavone metabolism from microbiome development in infants.

Several large, well-conducted studies of dietary genistein in Sprague-Dawley rats have been conducted at this institution under the auspices of the National Toxicology Program. These included a 2-year toxicology and carcinogenesis study (NTP, 2008a) a multigenerational 20week reproductive toxicology study (NTP, 2008b), and a serum/tissue pharmacokinetic analysis (Chang et al., 2000). Key design features included: dietary exposure levels relevant to defined human populations, including infants consuming soy formula; continuous exposure from conception through fetal, neonatal, weaning, and adult lifestages; 25 litters per exposure group across a total of 5 generations $\left(\mathrm{F}_{0}-\mathrm{F}_{4}\right)$; complete histopathological examination of organs for evidence of subtle reproductive tract lesions and tumorigenesis. The high dose group received 500 ppm genistein in a soy-free diet, which was equivalent to daily doses in the range of 35-51 $\mathrm{mg}$ per $\mathrm{kg}$ of body weight, and produced total genistein concentrations in adult rat serum in the range of 6-8 $\mu \mathrm{M}$ (Chang et al., 2000) and aglycone genistein concentrations estimated at 0.07$0.09 \mu \mathrm{M}$ (Doerge et al., 2002). The reproductive toxicology study reported adverse effects in the 500 ppm genistein dose group, including: accelerated vaginal opening, decreased anogenital distance, and altered estrous cyclicity in females; hyperplasia of the mammary gland and calcification of the renal tubules in males; and decreased body weights in males and females. Very limited evidence was observed to support carryover of effects into unexposed generations. The toxicology and carcinogenesis study reported "no evidence of carcinogenic activity" in 
males with continuous exposure and "some evidence of carcinogenic activity" in females with continuous exposure to the $500 \mathrm{ppm}$ dose based on increased incidences of mammary gland adenomas and adenocarcinomas (combined) and pituitary gland neoplasms. Exposure to 500 ppm genistein, either continuously or from gestation through weaning (GD6-PND21), produced earlier onset of aberrant estrous cycling than in untreated controls. The study authors concluded that "The effects of genistein on estrous cycling and the incidences of common hormonally related spontaneous neoplasms of female Sprague-Dawley rats are consistent with an estrogenic mechanism of action." These results in rats constitute much of the "clear evidence for adverse effects" cited by the NTP review of soy infant formula for developmental effects of genistein; however, evidence for potentially adverse effects of soy infant formula consumption on testicular function in male marmoset monkeys has also been reported (Sharpe et al., 2002; Tan et al., 2006).

The circulating levels of genistein aglycone achieved in neonatal monkeys in the range of 0.5-1 $\mu \mathrm{M}$ for extended times (Figures 5, S1, and S2) clearly exceed those measured in SpragueDawley rat pups nursing on dams ingesting daily dietary doses of genistein of approximately 50 mg/kg bw on either PND1-2 (47 nM, Doerge et al., 2001) or PND10 (47 nM) (Doerge et al., 2006). Based only on considerations of circulating levels of genistein and its ER binding affinity, this comparison suggests that any of the developmental effects in rats mediated by the neonatal portion of the lifetime exposure to genistein could be greater in young primates consuming soy formula.

\subsection{Conclusions}

This study of soy infant formula in developing monkeys, and the resulting internal exposures to active aglycone and conjugated forms, provides information about isoflavone metabolism and disposition that is unlikely to be to be obtained in studies using human infants. The experimental design includes dosing with isoflavone glucosides at doses within the daily range of human infant consumption in a commercial formula matrix using newborn subjects from a species closely related to humans based on similarities in physiology, metabolism, and pharmacology. The greater internal exposure observed in young monkeys relative to adults highlights the opposite roles that allometry and immaturity of important metabolic and/or excretory functions can play and reinforces the notion that adult-based administered dose alone is typically 
inadequate for predicting internal exposures in young children, especially the newborn (Mahmood, 2015).

Finally, the current study with isoflavones in a neonatal monkey pharmacokinetic model makes for an interesting comparison with results from the same animal model using bisphenol A (BPA), a ubiquitous anthropogenic chemical with similar or lower affinity to classical ERs than genistein (Doerge et al., 2010). Despite repeated determinations of safety by major food regulatory bodies, including the U.S. Food and Drug Administration and European Food Safety Authority, a high degree of risk perception is often associated with children's ingestion of BPA in a range below $1 \mu \mathrm{g} / \mathrm{kg}$ bw per day (Environmental Working Group, 2013). Such an exposure produces low internal exposures in newborn monkeys (0.01-0.02 $\mathrm{nM}$ peak serum concentration per $\mu \mathrm{g} / \mathrm{kg}$ bw ingested) that are similar to those in adult monkeys. This contrasts with the perceived safety of soy formula (NTP, 2010; Vandenplas et al., 2014) despite the much larger doses of soy isoflavones consumed $(\leq 10 \mathrm{mg} / \mathrm{kg}$ bw per day) that produce substantially higher internal exposures (50-100 $\mathrm{nM}$ peak serum concentration per $\mu \mathrm{g} / \mathrm{kg}$ bw ingested) and show significant evidence for immature clearance in neonatal primates relative to adults. This dichotomy likely reflects the roles that natural vs. synthetic chemicals and individual vs. corporate choices predictably play in shaping risk perception and the limited ability of public institutions to bridge "The Risk Perception Gap" engendered by basic cognitive processes shared by different groups within scientists and the lay public alike (Ropeik, 2015).

\section{Conflict of Interest}

The authors declare that there are no conflicts of interest.

Acknowledgements

This research was supported in part by NIH Grant Numbers P01AG024387 from National Institute of Aging, the Office of Dietary Supplements, and the National Cancer Institute and P50AT006268 from the National Center for Complementary and Integrative Health, the Office of Dietary Supplements, and the National Cancer Institute (to WGH and DRD). SCF was supported by a fellowship within the postdoctoral program of the German Academic Exchange Service (DAAD). KAW and SCF were supported by the Oak Ridge Institute for Science and Education (ORISE), administered through an interagency agreement between the U.S. 
Department of Energy and the U.S. Food and Drug Administration. The assistance of Melissa Ferguson (Alpha Genesis Inc.) in coordinating the monkey procedures is gratefully acknowledged. The findings and conclusions in this report are those of the authors and do not necessarily represent the views of the U.S. Food and Drug Administration. The authors have no conflicts of interest to report.

Appendix A. Supplementary material

Supplementary data associated with this article can be found, in the online version, at. 


\section{References}

Allred, C.D., Twaddle, N.C., Allred, K.F., Churchwell, M.I., Ju, Y.H., Helferich, W.G. Doerge, D.R. 2005. The effect of processing on soy isoflavone metabolism and disposition following dietary exposure in ovariectomized Balb/c mice. J. Ag. Fd. Chem. 53, 8542-8550.

Andrade, J. E., Twaddle, N.C., Helferich, W.G.and Doerge, D.R. 2010. Absolute Bioavailability of Isoflavones from Soy Protein Isolate-Containing Food in Female Balb/C Mice. J. Agric. Food Chem. 58, 4529-4536.

Bloedon, L. T., Jeffcoat, A. R., Lopaczynski, W., Schell, M. J., Black, T. M., Dix, K. J., Thomas, B. F., Albright, C., Busby, M. G., Crowell, J. A. and Zeisel, S. H.. 2002. Safety and pharmacokinetics of purified soy isoflavones: single-dose administration to postmenopausal women. Am. J. Clin. Nutr., 76, 1126-1137.

Cao, Y., Calafat, A.M., Doerge, D.R., Umbach, D.M., Bernbaum, J.C., Twaddle, N.C., Ye, X., and Rogan, W.J. 2009. Isoflavones in urine, saliva, and blood of infants - data from a pilot study on the estrogenic activity of soy formula. J. Expo. Sci. Environ. Epidemiol. 19, 223-234.

Chang, H.C., Churchwell, M.I., Delclos, K. B., Newbold, R.R., and Doerge, D.R. 2000. Mass spectrometric determination of genistein tissue distribution in Sprague-Dawley rats from dietary exposure J. Nutr. 130, 1963-1970.

Chellman, G.J., Bussiere, J.L., Makori, N., Martin, P.L., Ooshima, Y., and Weinbauer, G.F. 2009. Developmental and reproductive toxicology studies in nonhuman primates. Birth Defects Res. (Pt. B) 86, 446-462.

Chen, A. and Rogan, W.J. 2004. Isoflavones in soy infant formula: A review of evidence for endocrine and other activity in infants. Annu. Rev. Nutr. 24, 33-54.

Clancy, B., Finlay, B.L., Darlington, R.B., and Anand, K.J.S. 2007. Extrapolating brain development from experimental species to humans. NeuroToxicology 28, 931-937.

Coldham, N.G., Zhang, A.-Q., Key, P., and Sauer, M.J. 2002a . Absolute bioavailability of [14C] genistein in the rat; plasma pharmacokinetics of parent compound, genistein glucuronide, and total radioactivity. Eur. J., Drug Metab. Pharmacokinet. 27, 249-258.

Coldham, N.G., Darby, C., Hows, M., King, L.J., Zhang, A.-Q., and Sauer, M.J. 2002b. Comparative metabolism by human and rat gut microflora: detection and identification of the end-products of metabolism. Xenobiotica 32, 45-62.

Coughtrie, M.W.H., Burchell, B., Leakey, J.E.A., and Hume, R. 1988. The inadequacy of perinatal glucuronidation: Analysis of the developmental expression of individual UDPglucuronosyltransferase isoenzymes in rat and human liver microsomes. Mol. Pharmacol. 34, 729-735. 
Doerge, D.R., Chang, H.C., Holder, C.L., and Churchwell, M.I. 2000. Enzymatic conjugation of the soy isoflavones, genistein and daidzein, and analysis in human blood using liquid chromatography and mass spectrometry. Drug Metab. Disp. 28, 298-307.

Doerge, D.R., Churchwell, M.I., Chang, H.C., Newbold, R.R., and Delclos, K.B. 2001. Placental transfer of the soy isoflavone, genistein, following oral administration to Sprague Dawley rats. Reproductive Toxicol. 15, 105-110.

Doerge, D.R., Luecke, R.H., and Young, J.F. Metabolism and disposition of genistein, the principal soy isoflavone. 2002. In Phytoestrogens and Health, Eds. G.S. Gilani and J. Anderson, AOCS Press, Champaign, IL, pp.196-208.

Doerge, D.R. Twaddle, N.C. Newbold, R.R. and Delclos. K.B. 2006. Lactational transfer of the soy isoflavone, genistein, in Sprague-Dawley rats consuming dietary genistein. Repro. Toxicol. 21, 307-312.

Doerge, D.R., Twaddle, N.C., and Fisher, J.W. 2010. Pharmacokinetics of bisphenol A in adult and neonatal rhesus monkeys. Toxicol. Appl. Pharmacol. 248, 1-11.

Doerge, D.R., Twaddle, N.C., Vanlandingham, M., and Fisher, J.W. 2011. Pharmacokinetics of bisphenol A in adult and neonatal CD-1 mice: Inter-species comparisons with Sprague-Dawley rats and rhesus monkeys. Toxicol. Lett. 207, 298-305.

Environmental Working Group. 2013. Dirty Dozen Endocrine Disruptors. 12 HormoneAltering Chemicals and How to Avoid Them.

http://www.ewg.org/research/dirty-dozen-list-endocrine-disruptors

Falk, G. 1955. Maturation of renal function in infant rats. Am. J. Physiol. 181, 157-170.

Ginsberg, G., Hattis, D., Sonawane, B., Russ, A., Banati, P., Kozlak, M., Smolenski, S., and Goble, R. 2002. Evaluation of child/adult pharmacokinetic differences from a database derived from the therapeutic drug literature. Toxicol. Sci. 66, 185-200.

Gu, L., House, S.E., Prior, R.L., Fang, N., Ronis, M.J.J., Clarkson, T.B., Wilson, M.E., and Badger, T.M. 2006. Metabolic phenotype of isoflavones differ among female rats, pigs, monkeys, and women. J. Nutr. 136, 1215-1221.

Helferich, W.G., Andrade, J.E., and Hoagland, M.S. 2008. Phytoestrogens and breast cancer: a complex story. Inflammopharmacology 16, 219-226.

Jefferson, W.N., Doerge, D.R., Woodling, K.A., Padilla-Banks, E., Kissling, G., and Newbold, R.R. 2009. Oral exposure to genistin, the glycosylated form of genistein found in soy products, 
during neonatal life causes adverse effects on reproductive tissues of female mice. Environ. Health Persp. 117, 1883-1889.

Ju, Y.H., Fultz, J., Allred, K.F., Doerge, D.R., and Helferich, W.G. 2006. Effects of dietary daidzein and its metabolite, equol, at physiological concentrations on the growth of estrogendependent human breast cancer (MCF-7) tumor implanted in ovariectomized athymic mice. Carcinogenesis 27, 856-863.

Lagari, V.S. and Levis, S. 2014. Phytoestrogens for menopausal bone loss and climacteric symptoms. J. Ster. Biochem. Mol. Biol. 139, 294-301.

Mahmood, I. 2015. Prediction of drug clearance in children: a review of different methodologies. Expert Opin. Drug Metab. Toxicol. 11, 573-587.

Mattison, D.R., Karyakina, N., Goodman, M., and LaKind, J.S. 2014. Pharmaco- and toxicokinetics of selected exogenous and endogenous estrogens: A review of the data and identification of knowledge gaps. Crit. Rev. Toxicol. 44, 696-724.

McCarver, G., Bhatia, J., Chambers, C., Clarke, R., Etzel, R., Foster, W., Hoyer, P., Leeder, J.S., Peters, J.M., Rissman, E., Rybak, M., Sherman, C., Toppari, J., and Turner, K. 2011. NTPCERHR expert panel report on the developmental toxicity of soy infant formula. Birth Defects Res B Dev Reprod Toxicol. 92, 421-468.

Messina, M. 2014. Soy foods, isoflavones, and the health of postmenopausal women. Am. J. Clin. Nutr. 100(suppl), 423S-430S.

National Research Council. 1999. Hormonally Active Agents in the Environment. National Academy Press, Washington, D.C.

National Toxicology Program. 2008a. NTP Technical Report on the Toxicology and Carcinogenesis Study of Genistein (CAS No. 446-72-0) in Sprague-Dawley Rats (Feed Study). NTP TR 545, National Institutes of Health, Public Health Service, U.S. Department of Health and Human Services. http://ntp.niehs.nih.gov/ntp/htdocs/LT_rpts/TR545.pdf

National Toxicology Program. 2008b. NTP Technical Report on the Multigenerational Reproductive Toxicology Study of Genistein (CAS No. 446-72-0) in Sprague-Dawley Rats (Feed Study). NTP TR 539, National Institutes of Health, Public Health Service, U.S. Department of Health and Human Services. http://ntp.niehs.nih.gov/ntp/htdocs/LT_rpts/tr539.pdf

National Toxicology Program. 2010. NTP-CERHR Monograph on Soy Infant Formula. NIH Publication No. 10-5995 National Institutes of Health, Public Health Service, U.S. Department of Health and Human Services. http://ntp.niehs.nih.gov/ntp/ohat/genistein soy/soyformula/soymonograph2010_508.pdf 
Nicholson, J.K.Holmes, E., Kinross, J., Burcelin, R., Gibson, G., Jia, W., and Petterson, S. 2012. Host-gut microbiota interactions. Science 336, 1262-1267.

Nohynek, G.J., Borgert, C.J., Dietrich, D., and Rozman, K.K. 2013. Endocrine disruption: Fact or urban legend? Toxicol. Lett. 223, 295-305.

Ropeik, D. 2015. On the roots of, and solutions to, the persistent battle between "chemonoia" and rationalist denialism of the subjective nature of human cognition. Hum. Exp. Toxicol. 34, 1272-1278.

Sepehr, E., Cooke, G., Robertson, P., and Gilani, G.S. 2007. Bioavailability of soy isoflavones in rats. Part I: application of accurate methodology for studying the effects of gender and source of isoflavones. Mol. Nutr. Food Res. 51, 799-812.

Setchell, K.D.R., Zimmer-Nechemias, L., Cai, J., and Heubi, J.E. 1997. Exposure of infants to phyto-estrogens from soy-based infant formula. Lancet 350, 23-27.

Setchell, K.D.R., Faughnan, M.S., Avades, T., Zimmer-Nechemias, L., Brown, N.M., Wolfe, B.E., Brashear, W.T., Desai, P., Oldfield, M.F., Botting, N.P., and Cassidy, A. 2003.

Comparing the pharmacokinetics of daidzein and genistein with the use of 13C-labeled tracers in premenopausal women. Am. J. Clin. Nutr. 77, 411-419.

Sfakianos, J., Coward, L., Kirk, M., and Barnes, S. 1997. Intestinal uptake and biliary excretion of the isoflavone genistein in rats. J. Nutr. 127, 1260-1268.

Sharpe, R.M., Morris, M.B., Morris, K., Greig, I., McNeilly, A.S., and Walker, M. 2002. Infant feeding with soy formula milk: effects on the testis and on blood testosterone levels in marmoset monkeys during the period of neonatal testicular activity. Hum. Reprod. 17, 1692-1703.

Strassburg, C.P., Strassburg, A., Kneip, S., Barat, A., Tukey, R.H., Rodeck, B., and Manns, M.P. 2002. Developmental aspects of human hepatic glucuronidation in young children and adults. Gut 50, 259-265.

Tan, K.A., Walker, M., Morris, K., Greig, I., Mason, J.I., and Sharpe, R.M. 2006. Infant feeding with soy formula milk: effects on puberty progression, reproductive function and testicular cell numbers in marmoset monkeys in adulthood. Hum. Reprod.21, 896-904.

Twaddle, N.C., Churchwell M.I., and Doerge, D.R. 2002. High Throughput Quantification of Soy Isoflavones in Human and Mouse Plasma Using LC with Electrospray-MS and MS/MS Detection. J. Chrom. B 777, 137-143.

Vandenplas, Y., Castrellon, P.G., Rivas, R., Guiterrez, C.J., Garcia, L.D., Jimenez, J.E., Anzo, A., Hegar, B., and Alarcon, P. 2014. Safety of soya-based infant formulas in children. Br. J. Nutr. 111, 1340-1360. 
WHO (World Health Organization)/UNEP (United Nations Environment Programme) 2013. The State-of-the-Science of Endocrine Disrupting Chemicals - 2012 (Bergman A, Heindel JJ, Jobling S, Kidd KA, Zoeller RT, eds). Geneva:UNEP/WHO. Available:

http://www.who.int/ceh/publications/endocrine/en/index.html

Yang, Z., Kulkarni, K., Zhu, W., and Hu, M. 2012. Bioavailability and pharmacokinetics of genistein: mechanistic studies on its ADME. Anticancer Agents Med. Chem. 12, 1264-1280.

Zhang, L., Zuo, Z., and Lin, G. 2007. Intestinal and hepatic glucuronidation of flavonoids. Molec. Pharmaceutics 4, 833-845.

Zhou, S., Hu, Y., Zhang, B., Teng, Z., Gan, H., Yang, Z., Wang, Q., Huan, M., and Mei, Q. 2008. Dose-dependent absorption, metabolism, and excretion of genistein in rats. J. Agric. Food Chem. 56, 8354-8359. 
Table 1. Serum Pharmacokinetic Parameters for Genistein from Adult Male Rhesus Monkeys Administered a Single IV (5.2 mg/kg bw; mean $\pm \mathrm{SD}, \mathrm{n}=5)$ or Oral Dose $(2.8 \mathrm{mg} / \mathrm{kg}$ bw; mean $\pm \mathrm{SD}, \mathrm{n}=4)$.

\begin{tabular}{|c|c|c|c|c|c|c|c|}
\hline Route-Form & $\begin{array}{l}\mathrm{t}_{1 / 2 \operatorname{Elim}} \\
(\mathrm{h})^{1}\end{array}$ & $\begin{array}{l}\mathrm{t}_{1 / 2 \text { Distr }} \\
\text { (h) }\end{array}$ & $\begin{array}{l}\mathrm{C}_{\max } \\
(\mu \mathrm{M})\end{array}$ & $\begin{array}{l}\mathrm{AUC}_{0-24} \\
\left(\mu \mathrm{mol} \times \mathrm{h} \times \mathrm{L}^{-1}\right)\end{array}$ & $\begin{array}{l}\mathrm{V}_{\mathrm{d}} \\
\left(\mathrm{Lx} \mathrm{kg}^{-1}\right)\end{array}$ & $\begin{array}{l}\mathrm{Cl}_{\text {tot }} \\
\left(\mathrm{L} \mathrm{x} \mathrm{h}^{-1}\right)\end{array}$ & $\mathrm{f}$ \\
\hline IV - total & $7.6 \pm 1.5$ & & -- & $33 \pm 3.6$ & -- & -- & -- \\
\hline IV -aglycone & $12 \pm 9.2$ & $0.35 \pm 0.14$ & -- & $7.8 \pm 2.5$ & $35 \pm 16$ & $18 \pm 5.7$ & -- \\
\hline oral - total & $3.7 \pm 0.61$ & -- & $0.72 \pm 0.46$ & $4.3 \pm 2.4$ & -- & -- & $0.36 \pm 0.24$ \\
\hline oral - aglycone & $1.4 \pm 1.9$ & -- & $0.027 \pm 0.023$ & $0.087 \pm 0.043$ & -- & -- & $0.025 \pm 0.011$ \\
\hline
\end{tabular}

${ }^{1} \mathrm{t}_{1 / 2 \text { Elim }}=$ half-time for terminal elimination phase; $\mathrm{t}_{1 / 2 \text { Distr }}=$ half-time for tissue distribution phase; AUC $\mathrm{C}_{0-24}=$ area under the timeconcentration curve from $0-24 \mathrm{~h} ; \mathrm{C}_{\max }=$ maximal observed serum concentration; $\mathrm{V}_{\mathrm{d}}=$ volume of distribution for parent compound per $\mathrm{kg} \mathrm{bw} ; \mathrm{Cl}_{\text {tot }}=$ total serum clearance for parent compound; $\mathrm{f}=$ fraction absorbed $\left(\mathrm{AUC}_{0-24}\right.$ for oral administration $/ 2.8 \mathrm{mg} / \mathrm{kg} \mathrm{bw} \div$ $\mathrm{AUC}_{0-24}$ for IV administration $/ 5.2 \mathrm{mg} / \mathrm{kg}$ bw from individual monkeys). Values for $\mathrm{C}_{\max }$ were determined in individual monkeys for which the $\mathrm{T}_{\max }$ values varied between 4 and $8 \mathrm{hr}$. 
Table 2. Serum Pharmacokinetic Parameters for Daidzein from Adult Male Rhesus Monkeys Administered a Single IV (3.2 mg/kg bw; mean $\pm \mathrm{SD}, \mathrm{n}=5)$ or Oral Dose $(1.6 \mathrm{mg} / \mathrm{kg}$ bw; mean $\pm \mathrm{SD}, \mathrm{n}=4)$.

\begin{tabular}{|l|l|l|l|l|l|l|l|}
\hline Route-Form & $\begin{array}{l}\mathrm{t}_{1 / 2 \text { Elim }} \\
(\mathrm{h})\end{array}$ & $\begin{array}{l}\mathrm{t}_{1 / 2 \text { Distr }} \\
(\mathrm{h})\end{array}$ & $\begin{array}{l}\mathrm{C}_{\max } \\
(\mu \mathrm{M})\end{array}$ & $\begin{array}{l}\mathrm{AUC}_{0-24} \\
\left(\mu \mathrm{mol} \times \mathrm{h} \mathrm{L} \mathrm{L}^{-1}\right)\end{array}$ & $\begin{array}{l}\mathrm{V}_{\mathrm{d}} \\
\left(\mathrm{L} \mathrm{x} \mathrm{kg}^{-1}\right)\end{array}$ & $\begin{array}{l}\mathrm{Cl}_{\text {tot }} \\
\left(\mathrm{L} \mathrm{x} \mathrm{h}^{-1}\right)\end{array}$ & $\mathrm{f}$ \\
\hline IV - total & $10 \pm 5.7$ & & -- & $38 \pm 43$ & -- & -- & -- \\
\hline IV -aglycone & $1.4 \pm 0.44$ & $0.24 \pm 0.08$ & -- & $4.4 \pm 1.7$ & $5.9 \pm 2.6$ & $22 \pm 8.8$ & -- \\
\hline oral - total & $3.0 \pm 2.3$ & -- & $0.65 \pm 0.33$ & $4.0 \pm 2.0$ & -- & -- & $0.42 \pm 0.23$ \\
\hline oral - aglycone & $1.0 \pm 0.89$ & -- & $0.014 \pm 0.006$ & $0.067 \pm 0.036$ & -- & -- & $0.039 \pm 0.029$ \\
\hline
\end{tabular}

${ }^{1} \mathrm{t}_{1 / 2 \text { Elim }}=$ half-time for terminal elimination phase; $\mathrm{t}_{1 / 2 \text { Distr }}=$ half-time for tissue distribution phase; $\mathrm{AUC} \mathrm{C}_{0-24}=$ area under the timeconcentration curve from $0-24 \mathrm{~h} ; \mathrm{C}_{\max }=$ maximal observed serum concentration; $\mathrm{V}_{\mathrm{d}}=$ volume of distribution for parent compound per $\mathrm{kg} \mathrm{bw} ; \mathrm{Cl}_{\text {tot }}=$ total serum clearance for parent compound; $\mathrm{f}=$ fraction absorbed $\left(\mathrm{AUC}_{0-24}\right.$ for oral administration $/ 1.6 \mathrm{mg} / \mathrm{kg} \mathrm{bw} \div$ $\mathrm{AUC}_{0-24}$ for IV administration $/ 3.2 \mathrm{mg} / \mathrm{kg} \mathrm{bw}$ ). Values for $\mathrm{C}_{\max }$ were determined in individual monkeys for which the $\mathrm{T}_{\max }$ values varied between 4 and $8 \mathrm{hr}$. 
Table 3. Serum Pharmacokinetic Parameters for Total Equol from Adult Male Rhesus Monkeys Administered a Single Dose of Daidzein by Either IV (3.2 mg/kg bw; mean $\pm \mathrm{SD}, \mathrm{n}=5)$ or Oral $(1.6 \mathrm{mg} / \mathrm{kg}$ bw; mean $\pm \mathrm{SD}, \mathrm{n}=4)$ Route.

\begin{tabular}{|l|l|l|l|}
\hline Route & $\begin{array}{l}\mathrm{C}_{\max } \\
(\mu \mathrm{M})\end{array}$ & $\begin{array}{l}\mathrm{AUC}_{0-24} \\
\left(\mu \mathrm{mol} \times \mathrm{h} \mathrm{x} \mathrm{L}^{-1}\right)\end{array}$ & AUC-Eq/AUC-Daid \\
\hline IV & $1.5 \pm 0.83$ & $20 \pm 11$ & $1.0 \pm 0.57$ \\
\hline oral & $2.1 \pm 1.5$ & $22 \pm 15$ & $5.0 \pm 3.5$ \\
\hline
\end{tabular}

${ }^{1} \mathrm{AUC}_{0-24}=$ area under the time-concentration curve from $0-24 \mathrm{~h}$ for total equol or daidzein; $\mathrm{C}_{\max }=$ maximal observed serum concentration.

Note: no aglycone equol was observed in any sample. 
Table 4. Serum Pharmacokinetic Parameters for Aglycone Genistein from Neonatal Rhesus Monkeys (PND 5-70) Administered a Single Oral Dose of $10.4 \mathrm{mg} / \mathrm{kg}$ bw (mean $\pm \mathrm{SD}, \mathrm{n}=5$ for PND 5, $\mathrm{n}=4$ for PND 35 and 70).

\begin{tabular}{|l|l|l|l|}
\hline Age & $\begin{array}{l}\mathrm{t}_{1 / 2 \text { Elim }} \\
(\mathrm{h})^{1}\end{array}$ & $\begin{array}{l}\mathrm{AUC}_{0-24} \\
\left(\mu \mathrm{mol} \times \mathrm{h} \mathrm{x} \mathrm{L}^{-1}\right)\end{array}$ & $\begin{array}{l}\mathrm{C}_{\max } \\
(\mu \mathrm{M})\end{array}$ \\
\hline PND 5 & $6.6 \pm 1.7^{*}$ & $11 \pm 5.9^{*}$ & $0.95 \pm 0.29^{*}$ \\
\hline PND 35 & $15 \pm 14^{*}$ & $5.7 \pm 3.8^{*}$ & $0.69 \pm 0.34^{*}$ \\
\hline PND 70 & $4.0 \pm 0.91^{*}$ & $2.3 \pm 1.1^{*}$ & $0.37 \pm 0.17^{*}$ \\
\hline
\end{tabular}

${ }^{1} t_{1 / 2 \text { Elim }}=$ half-time for terminal elimination phase; $\mathrm{AUC}_{0-24}=$ area under the time- aglycone genistein concentration curve from $0-24 \mathrm{~h} ; \mathrm{C}_{\max }=$ maximal observed serum aglycone genistein concentration.

*Significantly different from the corresponding adult values (dose-adjusted AUCs and $\mathrm{C}_{\max }$ values) by one-way ANOVA. 
Table 5. Serum Pharmacokinetic Parameters for Aglycone Daidzein from Neonatal Rhesus Monkeys (PND 5-70) Administered a Single Oral Dose of $6.0 \mathrm{mg} / \mathrm{kg}$ bw (mean $\pm \mathrm{SD}, \mathrm{n}=5$ for PND 5, $\mathrm{n}=4$ for PND 35 and 70).

\begin{tabular}{|l|l|l|l|l|}
\hline Age & $\begin{array}{l}\mathrm{t}_{1 / 2} \text { Elim } \\
(\mathrm{h})^{1}\end{array}$ & $\begin{array}{l}\mathrm{AUC}_{0-24} \\
\left(\mu \mathrm{mol} \times \mathrm{h} \mathrm{x} \mathrm{L}^{-1}\right)\end{array}$ & $\begin{array}{l}\mathrm{C}_{\max } \\
(\mu \mathrm{M})\end{array}$ & AUC-Eq/AUC-Daid \\
\hline PND 5 & $6.4 \pm 2.2^{*}$ & $6.6 \pm 2.3^{*}$ & $0.88 \pm 0.28^{*}$ & $0.05 \pm 0.05^{* *}$ \\
\hline PND 35 & $5.6 \pm 2.6^{*}$ & $3.4 \pm 1.5^{*}$ & $0.28 \pm 0.10^{*}$ & $0.19 \pm 0.15$ \\
\hline PND 70 & $4.6 \pm 1.2^{*}$ & $1.4 \pm 0.55^{*}$ & $0.34 \pm 0.18^{*}$ & $0.84 \pm 0.62$ \\
\hline
\end{tabular}

${ }^{1} \mathrm{t}_{1 / 2 \text { Elim }}=$ half-time for terminal elimination phase for aglycone daidzein; $\mathrm{AUC}_{0-24}=$ area under the time- aglycone daidzein concentration curve from $0-24 \mathrm{~h} ; \mathrm{C}_{\max }=$ maximal observed serum aglycone daidzein concentration.

"Significantly different from the corresponding adult values (dose-adjusted AUCs and $\mathrm{C}_{\max }$ values) by one-way ANOVA.

** Significantly different from the corresponding adult values by one-way ANOVA on ranks for non-normal log-transformed data. 
SCHEME 1. Metabolism of Genistein.

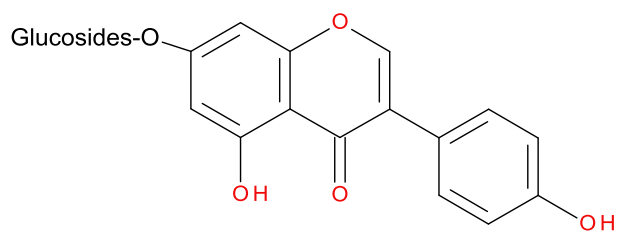

Glucoside Forms in Soy

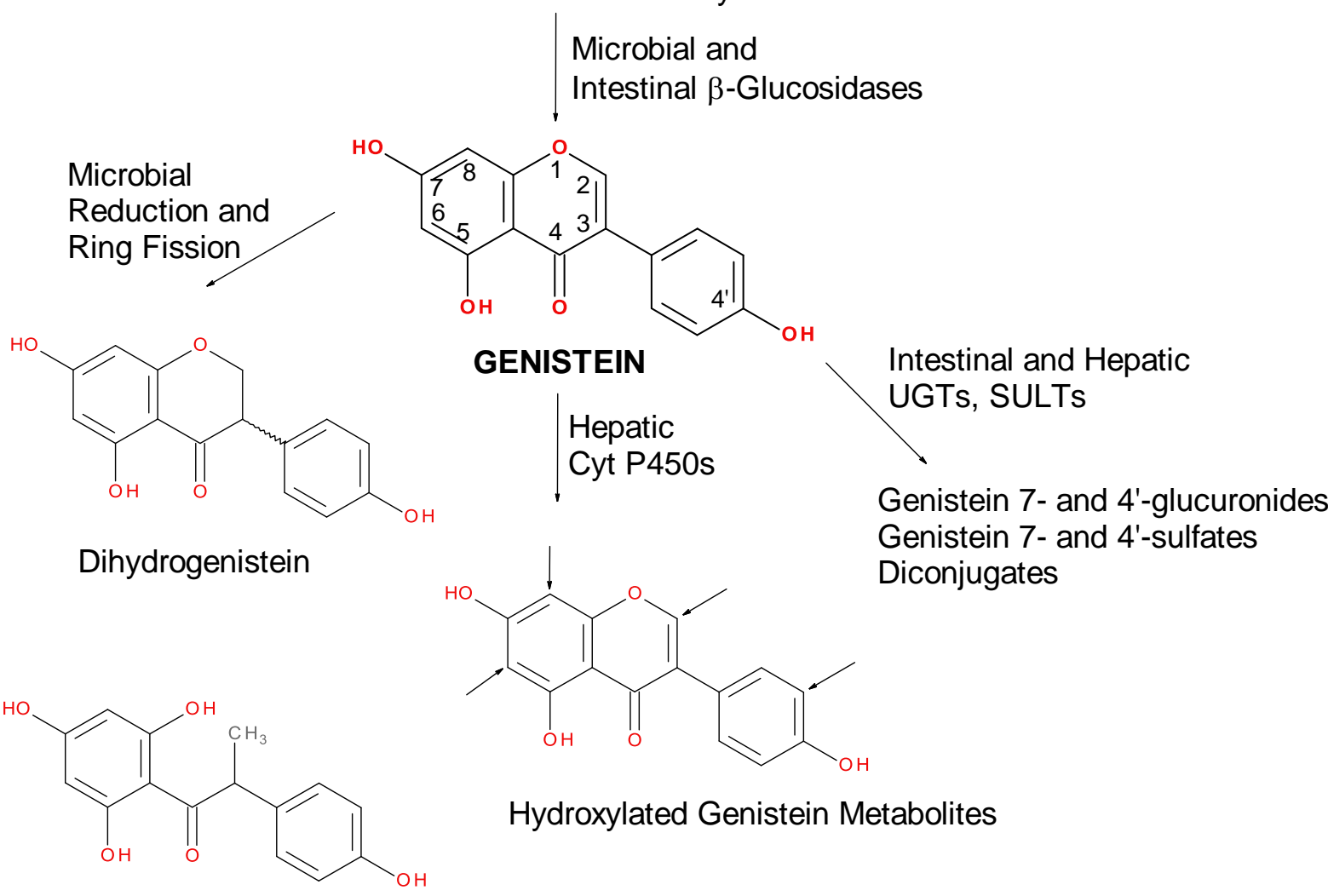

6'-Hydroxy-O-desmethylangolensin<smiles>CC(C(=O)O)c1ccc(O)cc1</smiles>

4-Hydroxyphenyl-2-propionic acid<smiles>CCc1ccc(O)cc1</smiles>

4-Ethylphenol 
SCHEME 2. Metabolism of Daidzein.

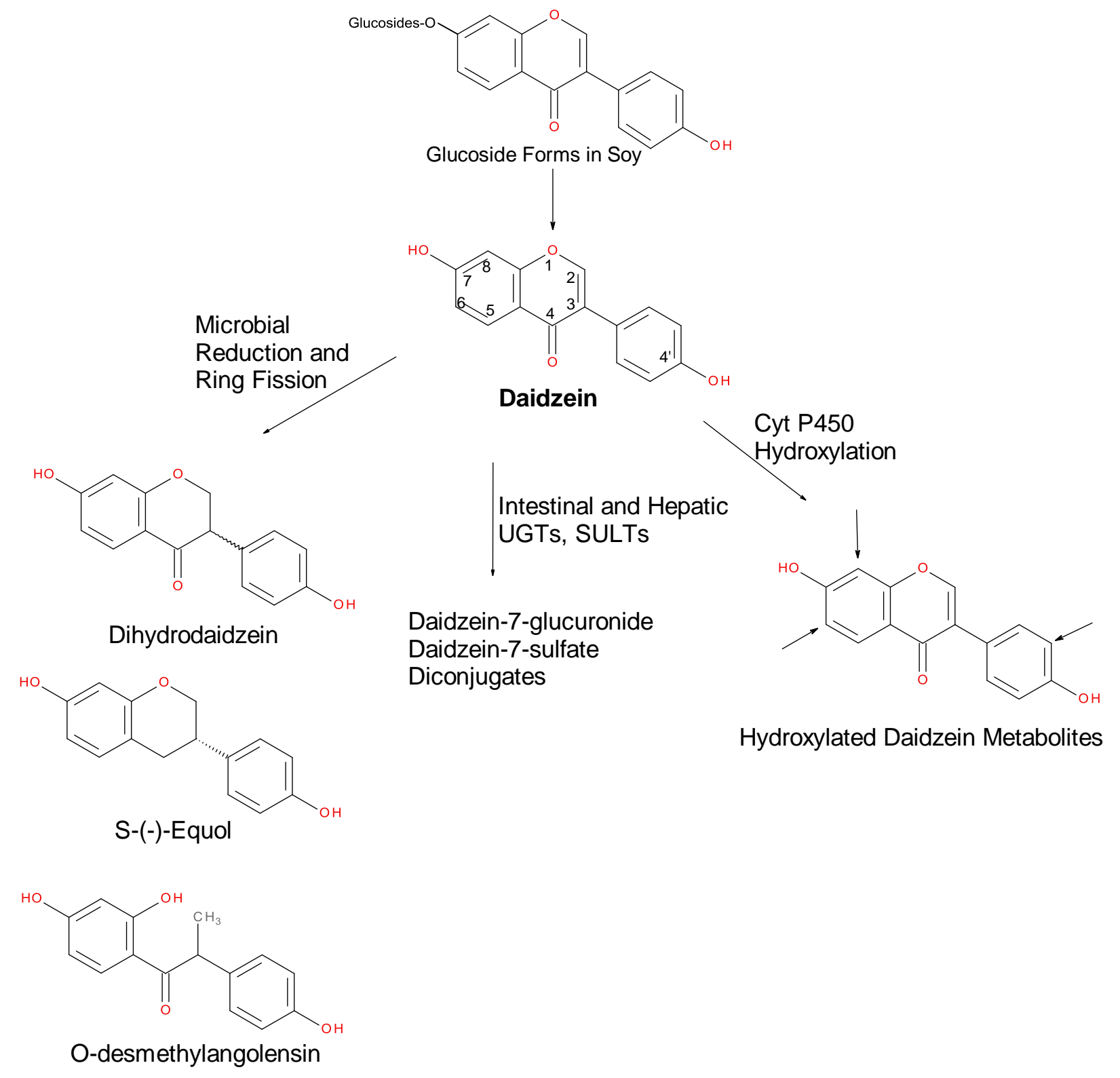




\section{FIGURE LEGENDS}

Figure 1. Average Serum Time-Concentration Profiles for Aglycone and Total Genistein and Daidzein from Adult Male Rhesus Monkeys ( $\mathrm{n}=5$ ) Following a Single IV Dose of $5.2 \mathrm{mg} / \mathrm{kg}$ bw and $3.2 \mathrm{mg} / \mathrm{kg} \mathrm{bw}$, respectively. Note that the data presented are the means $\pm \mathrm{SD}$ of the individual monkey time-serum concentrations and therefore cannot be compared directly with such plots (not shown) for the individual monkeys that were used to determine the individual and mean values for $\mathrm{t} 1 / 2$ shown in Tables 1 and 2 .
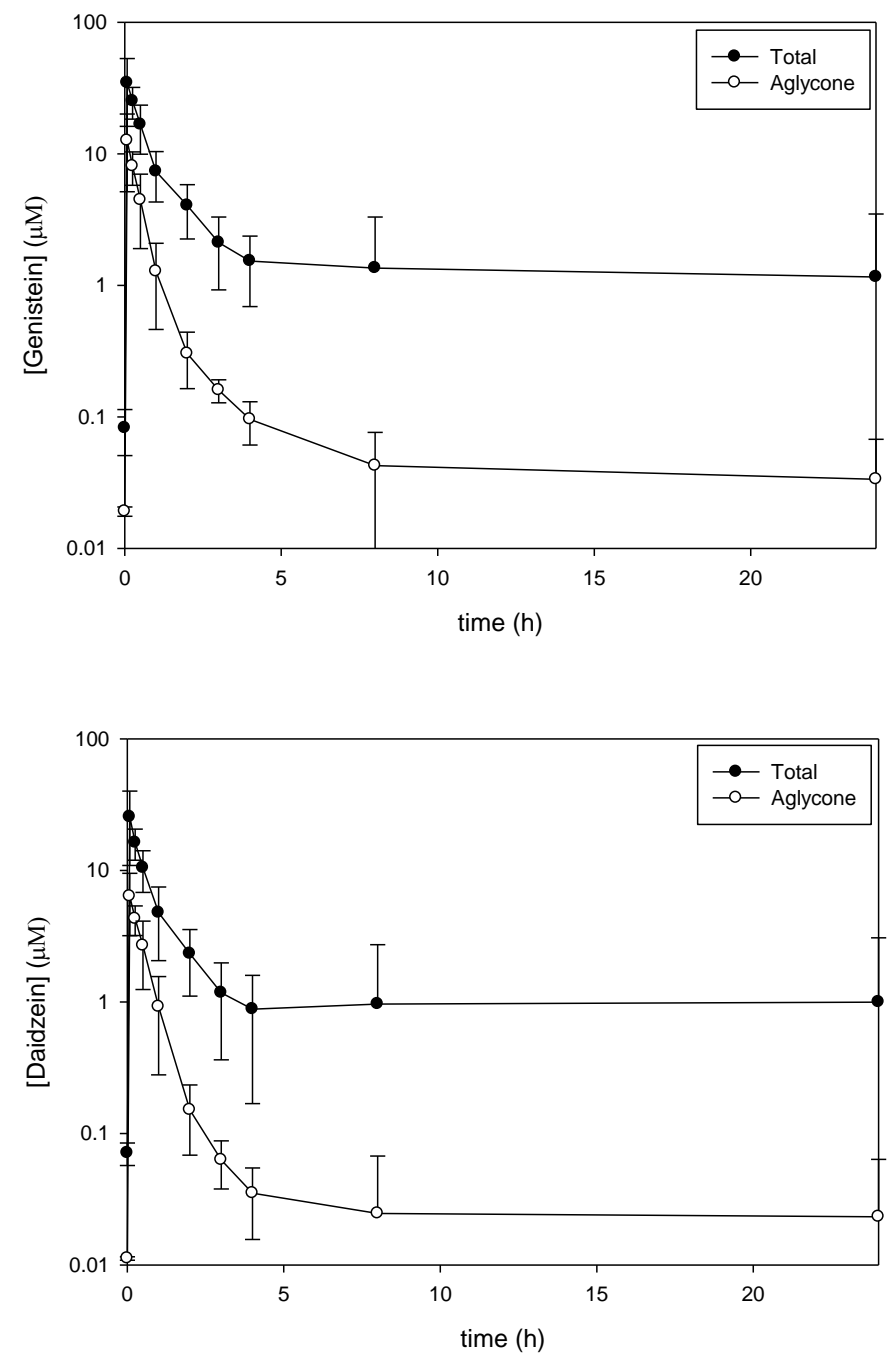
Figure 2. Average Serum Time-Concentration Profiles for Total Equol in Adult Male Rhesus Monkeys $(\mathrm{n}=5)$ Following a Single IV Dose of $3.2 \mathrm{mg} / \mathrm{kg}$ bw Daidzein. Note that the data presented are the means \pm SD of the individual time-serum concentrations and therefore cannot be compared directly with such plots (not shown) for the individual monkeys that were used to determine the individual and mean values for $t 1 / 2$ shown in Tables 1 and 2 . The reliance of t1/2Elim on the $24 \mathrm{hr}$ time point also serves to magnify differences and increase varialbility due to analytical and physiological variability associated with those measurements.

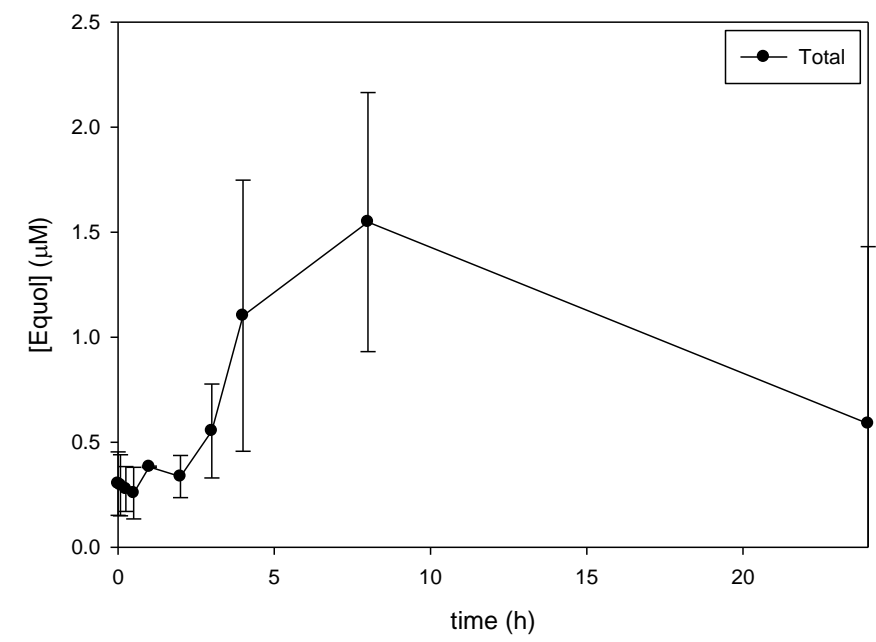


Figure 3. Average Serum Time-Concentration Profiles for Aglycone and Total Isoflavones from Adult Male Rhesus Monkeys ( $n=4)$ Following a Single Oral Dose of Fortified Soy Formula containing $2.8 \mathrm{mg} / \mathrm{kg}$ bw Genistein and $1.6 \mathrm{mg} / \mathrm{kg}$ bw Daidzein.
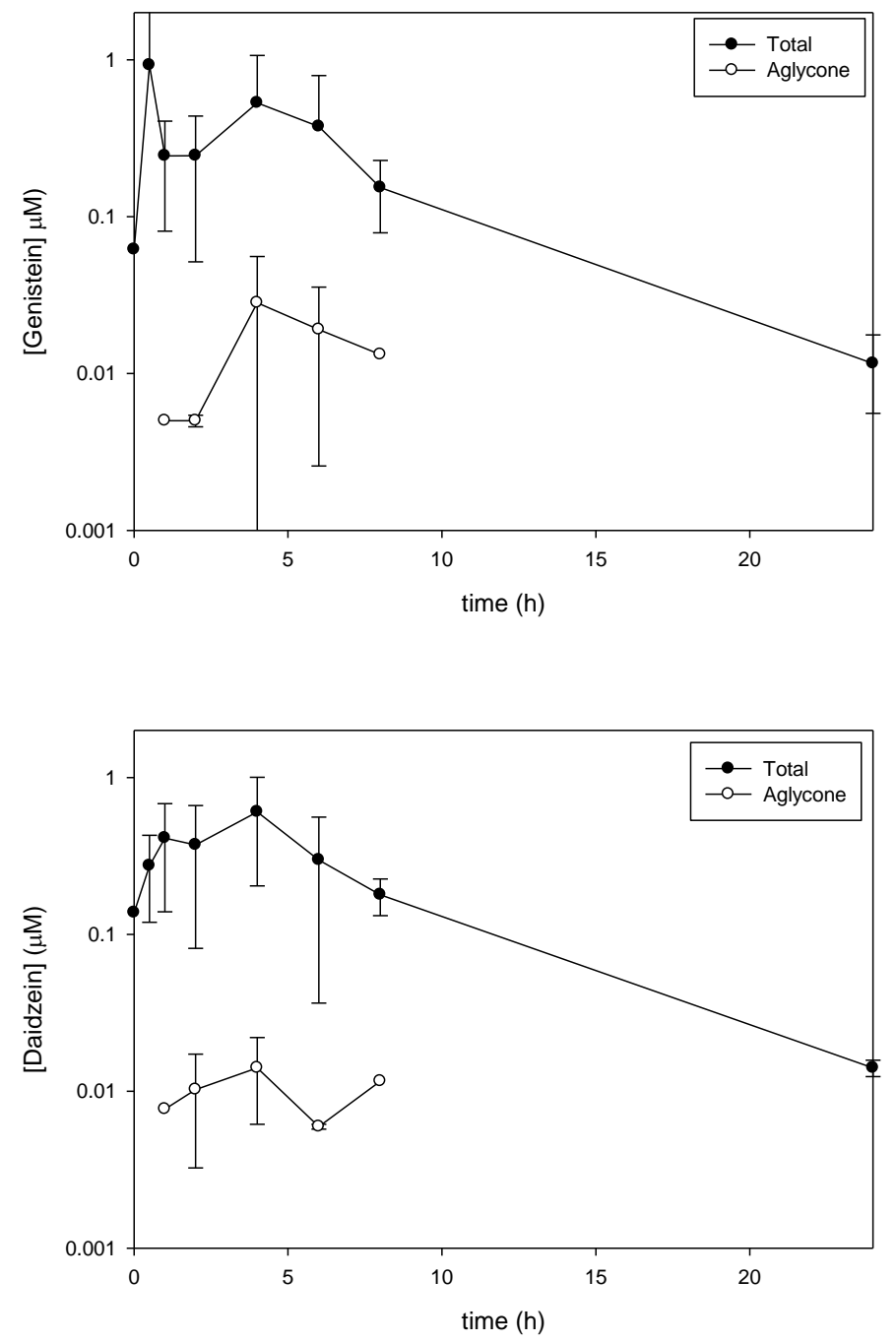
Figure 4. Average Serum Time-Concentration Profiles for Total Isoflavones and Equol from Adult Male Rhesus Monkeys ( $n=4)$ Following a Single Oral Dose of Fortified Soy Formula Containing $2.8 \mathrm{mg} / \mathrm{kg}$ bw Genistein and $1.6 \mathrm{mg} / \mathrm{kg}$ bw Daidzein.

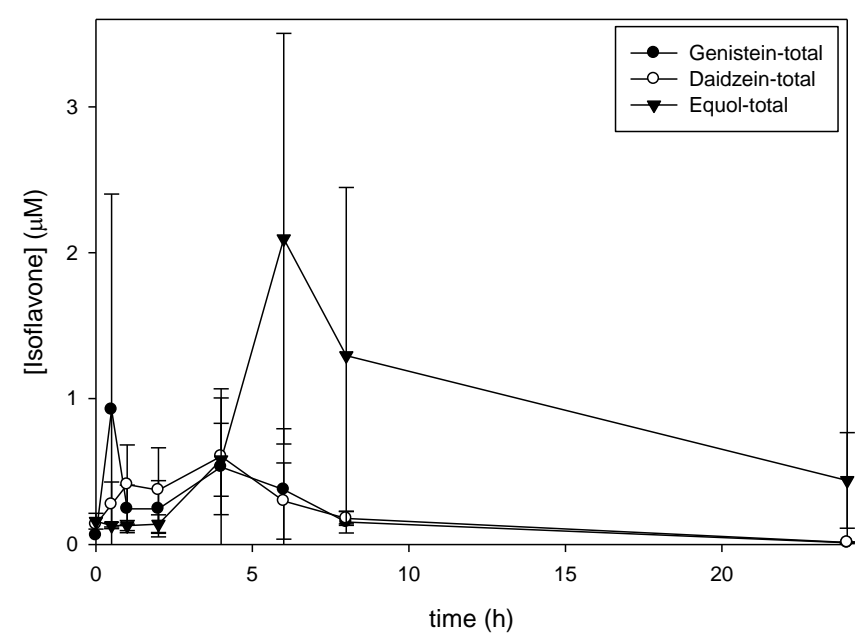


Figure 5. Average Serum Time-Concentration Profiles for Aglycone and Total Isoflavones from PND 5 Male Rhesus Monkeys ( $\mathrm{n}=5$ ) Following a Single Oral Dose of Fortified Soy Formula Containing $10.4 \mathrm{mg} / \mathrm{kg}$ bw Genistein and $6.0 \mathrm{mg} / \mathrm{kg}$ bw Daidzein.
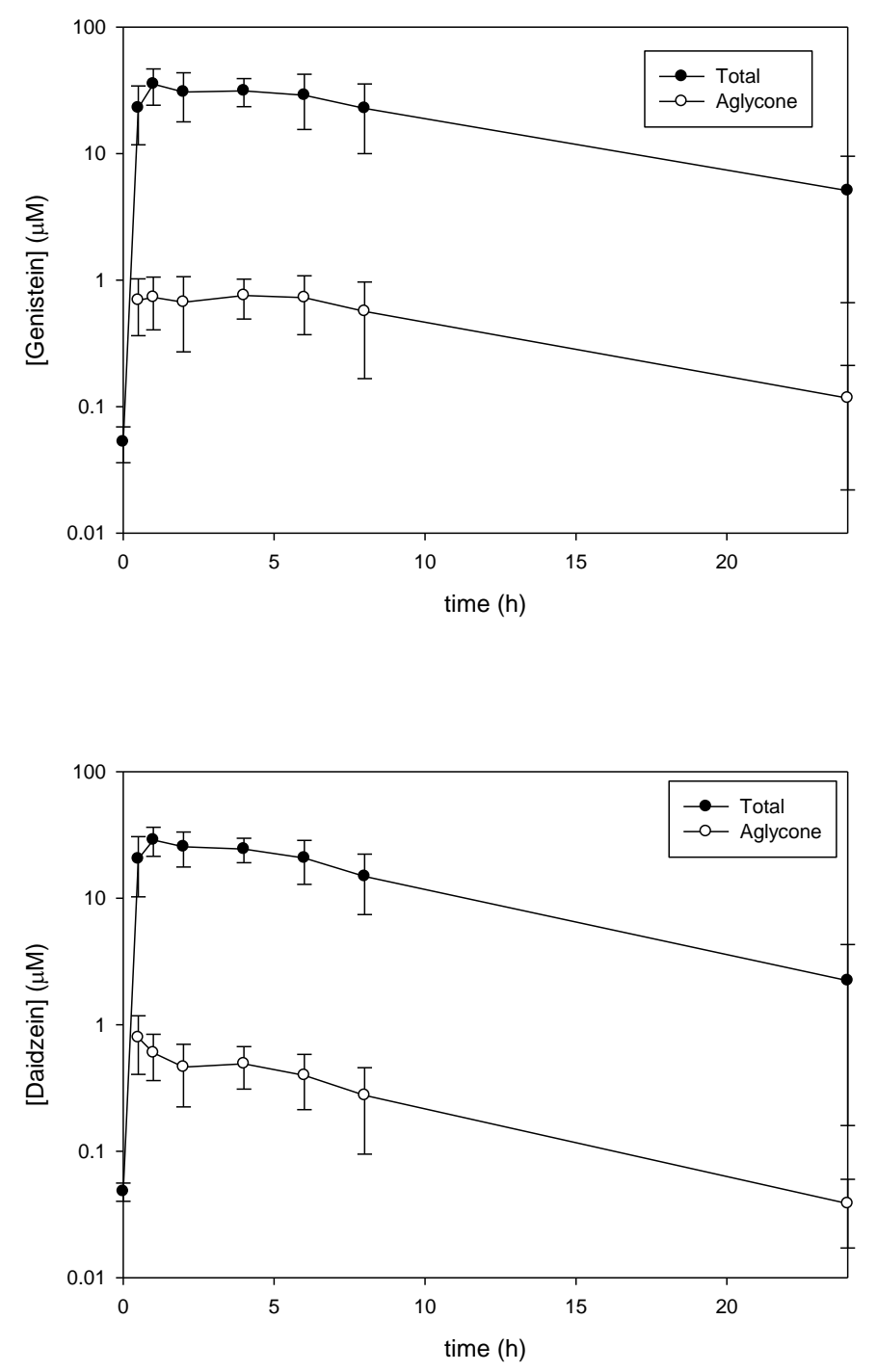
Figure 6. Average Serum Time-Concentration Profiles for Total Isoflavones and Equol from PND 5 Male Rhesus Monkeys ( $\mathrm{n}=5$ ) Following a Single Oral Dose of Fortified Soy Formula Containing $10.4 \mathrm{mg} / \mathrm{kg}$ bw Genistein and $6.0 \mathrm{mg} / \mathrm{kg}$ bw Daidzein.

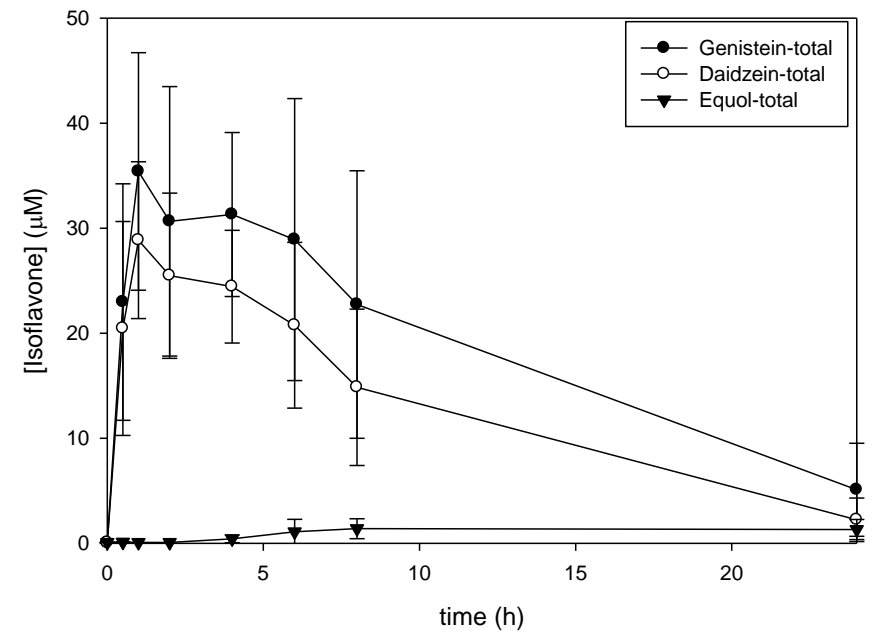


Figure 7. Comparison of Serum Pharmacokinetic Parameters for Aglycone Genistein Following a Single Oral Dose of Soy Formula in Neonatal (10.4 mg/kg bw; mean \pm SD, $\mathrm{n}=4-5)$ and Adult Rhesus Monkeys $(2.8 \mathrm{mg} / \mathrm{kg}$ bw; $\mathrm{n}=4)$. Statistical comparisons for AUC, $\mathrm{C}_{\max }$, or the fraction of aglycone in AUC (\%Aglycone) were made using one-way ANOVA for neonatal vs. adult monkey parameters (adult AUC and $\mathrm{C}_{\max }$ values adjusted for the dose difference; $*$ = significant difference between the adult group and neonatal groups by pairwise comparisons using Dunnett's test with $\mathrm{p}<0.05)$.

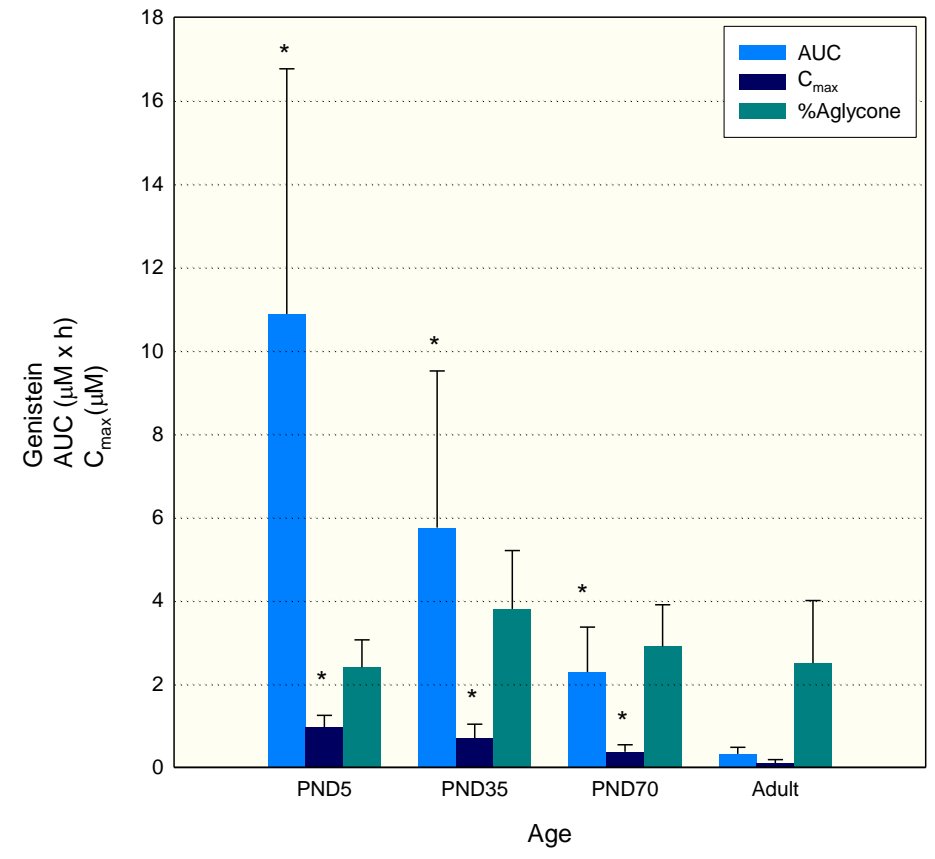


Figure 8. Comparison of Serum Pharmacokinetic Parameters for Aglycone Daidzein Following a Single Oral Dose in Soy Formula in Neonatal $(6.0 \mathrm{mg} / \mathrm{kg}$ bw; mean $\pm \mathrm{SD}, \mathrm{n}=4-5)$ and Adult Rhesus Monkeys $(1.6 \mathrm{mg} / \mathrm{kg}$ bw; $\mathrm{n}=4)$. Statistical comparisons were made using one-way ANOVA for neonatal vs. adult monkey parameters (adult AUC and $\mathrm{C}_{\max }$ values adjusted for the dose difference; $*=$ significant difference between the adult group and neonatal groups by pairwise comparisons using Dunnett's test with $\mathrm{p}<0.05) ; * *=$ significant difference between the adult and PND 5 groups for AUC-Equol/AUC-Daidzein by pairwise comparisons following one-way ANOVA on ranks for non-normal log-transformed data.

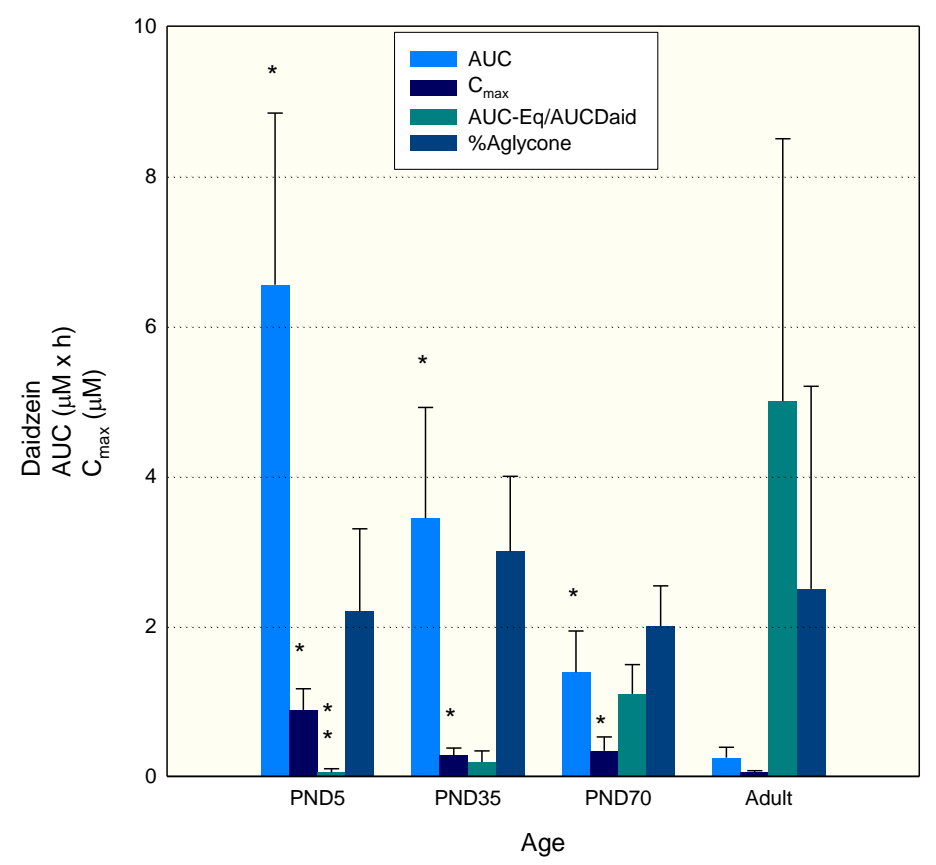

